\title{
Selection of Additive Manufacturing Technologies Using Decision Methods
}

\author{
Anderson Vicente Borille and Jefferson de Oliveira Gomes \\ Technological Institute of Aeronautics - ITA \\ Brazil
}

\section{Introduction}

The use of Rapid Prototyping technologies is becoming increasingly popular due to the reduction of machinery prices. Consequently, more and more industries now have the opportunity to apply such processes to improve their product development cycles.

The term Rapid Prototyping was commercially introduced to highlight the first application, the quickly production of prototypes into the product development process. Improvements were done in the quality of the equipments and the variety of materials. Furthermore, new processes were introduced into the market, which enlarged the application's range of Rapid Prototyping technologies. As a consequence, new terms were also used to describe the final application of such technologies as Rapid Manufacturing (RM); Rapid Tooling (RT), which indicates the use of such technologies to produce moulds and tooling, etc.

However, as important as to identify the technical limits of the each technology, it is needed to balance the characteristics of each process in order to decide which one fulfills the product requirements the best way. And this should be done systematically using a decision method. The decision method, in turn, should be able to evaluate the relative weights of product requirements related to the process capabilities. It is not just a matter of manufacturing process substitution. It is possible - and desirable in case of RM - to modify designing and product development processes too.

This chapter is divided into two sections. The first part considers prototyping applications, where the requirements of the part to be produced are not too severe. In this case, available process capabilities should be used to satisfy costumer's needs, usually at the lowest manufacturing cost and delivery time possible. The second section is intended to those who are concerned in Rapid Manufacturing Applications. Rapid Manufacturing means that the parts will be produced as end product, thus, the product requirements are more rigorous then prototyping applications.

\section{Part I: Rapid prototyping applications}

This chapter aims to present different decision making approaches to choose an adequate $\mathrm{RP}$ process. Here, four decision approaches were applied to compare six processes regarding six criteria, using the input data from previous works. As result, three decision methods were compared, additionally to the references. Two different scenarios were constructed, where different important attributes were considered, simulating two different 
prototype applications. It was demonstrated that not all methods result to the same RP ranking, however most of them provide the same first option for a given scenario. The characteristics of the methods could be related to their influence on the evaluation, which serve as guidelines for the decision makers in order to reflect their exact opinion or requirements. Although the fundamentals of the decision methods are presented here, one should be careful while comparing the RP process, because their attributes may vary enormously depending on the parameter process to build a part. Despite all the considerations and precautions to be observed, the selection of the RP process can be done in a simple way, dispensing complex calculations.

\subsection{Example of application}

The decision process requires the evaluation of alternative characteristics (attributes) regarding the desired requirements (criteria) to reach an objective. Byun and Lee (2005), based on questionnaires answered by users, concluded that the following six attributes are the most important regarding the use of RP processes: accuracy (A), surface roughness (R), tensile strength (E), elongation (S), cost of the part (C) and build time (B). Further, they gathered these attributes from six different RP processes, and proposed a method to evaluate these attributes simulating two different scenarios: Scenario 1) where the cost of the part (C) and build time (B) were considered most important factors, followed by $\mathrm{S}$ and $\mathrm{E}$, and $A$ and R, and Scenario 2) where accuracy (A) and surface roughness (S) where considered most important followed by S and E, and C and B. Later, Padmanabhan (2007) used the same RP processes attributes to evaluate similar conditions, but using Graph Theory \& Matrix Approach (GT\&MA) instead of Topsis. The attributes of the Alternatives presented in Table 1 were used by both previous works.

\begin{tabular}{ccccccc}
\hline Process & A & R & S & E & C & B \\
\hline Process1 & 120 & 6,5 & 65 & 5 & Very high & Medium \\
\hline Process2 & 150 & 12,5 & 40 & 8,5 & Very high & Medium \\
\hline Process3 & 125 & 21 & 30 & 10 & High & Very high \\
\hline Process4 & 185 & 20 & 25 & 10 & Slightly high & Slightly low \\
\hline Process5 & 95 & 3,5 & 30 & 6 & Very high & Slightly low \\
\hline Process6 & 600 & 15,5 & 5 & 1 & Very very low & Very low \\
\hline
\end{tabular}

Table 1. Alternatives attributes table (Byun and Lee, 2005; Rao and Padmanabhan, 2007)

Based on the information from the processes and from the requirements, a decision maker should be able to evaluate the alternatives and propose a recommendation. The issues to manage consist that most product requirements are contradictory. For example, in the Table 1 the process which has the lowest cost produces the weakest part. The decision maker should be able to answer - in a systematically form - how much more important is the cost in relation to tensile strength? Such questions are well complicated to be translated into numbers directly, but using established procedures the answer can be very consistent.

Decision Making processes are usually elaborated to be useful to a large range of applications, consequently, they have to be lapidated to be applied to each specific use. An important point of this work, is that for each decision approach, some kind of consideration had to be done in order to represent an approximated scenario to different decision 
methods. They were most related to the conversion of scales and weighting procedures. Even with these considerations, most decision methods provided the same process as the first option. Thus, the decision maker may feel free to use the most familiar way, just considering some rough characteristics.

\subsubsection{Analytic Hierarchy Process (AHP)}

The Analytic Hierarchy Process (AHP) is a multi-criteria decision-making approach and was introduced by Thomas L. Saaty (Saaty, 1977; Saaty 1990). The AHP has attracted the interest of many researchers mainly due to the mathematical properties of the method and the fact that the required input data is rather easy to obtain (Triantaphyllou, 1995, Guglielmetti et. al. 2003).

\section{a) Method}

The method is based on a pairwise comparison of alternatives and criteria of a hierarchical structure (Fig. 1). In order to evaluate the approach, a comparison matrix for the criteria must be described, as the Fig. 2.

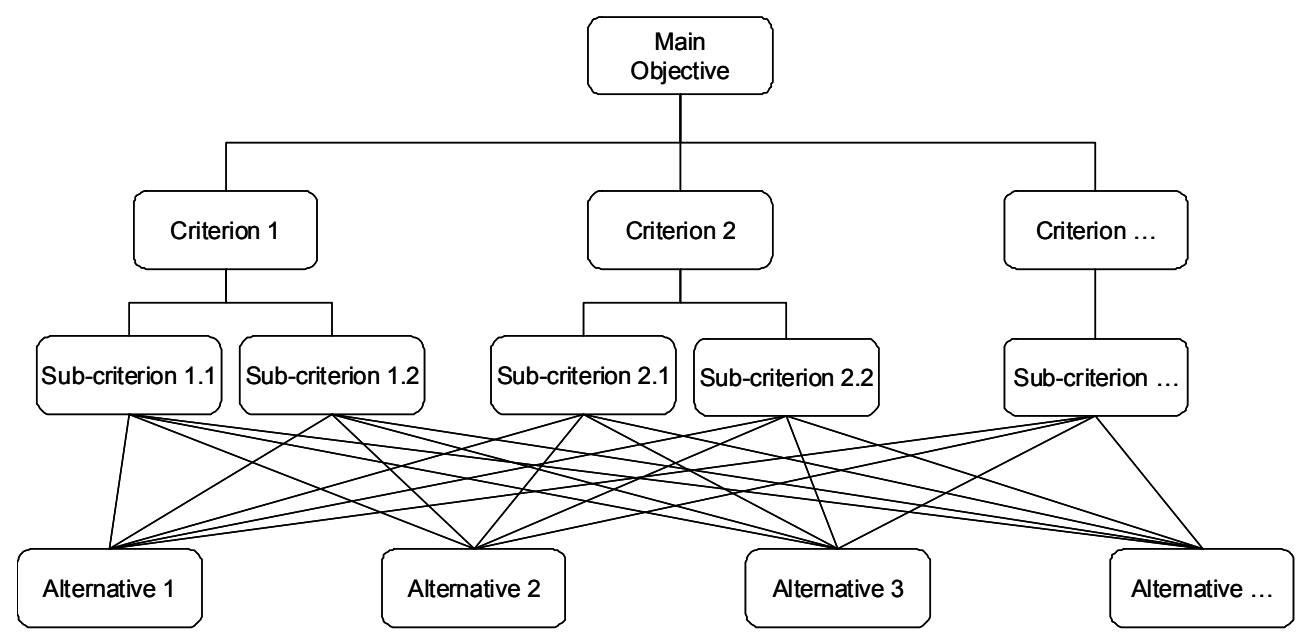

Fig. 1. The hierarchical structure of AHP approach (Saaty, 1977)

$$
\begin{aligned}
& \begin{array}{llll}
C_{1} & C_{2} & \ldots & C_{n}
\end{array} \\
& \left.\begin{array}{c|cccc}
C_{1} & \left(w_{1} / w_{1}\right. & w_{1} / w_{2} & \ldots & w_{1} / w_{n} \\
C_{2} & w_{2} / w_{1} & w_{2} / w_{2} & \ldots & w_{2} / w_{n} \\
. . & \ldots & \ldots & \ldots & \ldots \\
C_{n} & \ldots w_{n} / w_{1} & w_{n} / w_{2} & \ldots & w_{n} / w_{n}
\end{array}\right)
\end{aligned}
$$

Fig. 2. Comparison matrix fort the criteria (Saaty, 1977)

Each element $\mathrm{w}_{\mathrm{i}} / \mathrm{w}_{\mathrm{j}}$ have to represent how much the $i$ criteria is more important than the $j$, following the fundamental scale from Saaty (Table 2). 


\begin{tabular}{|c|c|c|}
\hline $\begin{array}{l}\text { Intensity of } \\
\text { importance }\end{array}$ & Definition & Explanation \\
\hline 1 & Equal importance & $\begin{array}{l}\text { Two activities contribute equally to the } \\
\text { objective }\end{array}$ \\
\hline 3 & $\begin{array}{l}\text { Moderate importance } \\
\text { of one over another }\end{array}$ & $\begin{array}{l}\text { Experience and judgment slightly favour one } \\
\text { activity over another }\end{array}$ \\
\hline 5 & $\begin{array}{l}\text { Essential or strong } \\
\text { importance }\end{array}$ & $\begin{array}{l}\text { Experience and judgment strongly favour one } \\
\text { activity over another }\end{array}$ \\
\hline 7 & $\begin{array}{l}\text { Very strong } \\
\text { importance }\end{array}$ & $\begin{array}{l}\text { An activity is strongly favoured and its } \\
\text { dominance demonstrated in practice }\end{array}$ \\
\hline 9 & Extreme importance & $\begin{array}{c}\text { The evidence favouring one activity over } \\
\text { another is of the highest possible order of } \\
\text { affirmation }\end{array}$ \\
\hline $2,4,6,8$ & $\begin{array}{l}\text { Intermediate values } \\
\text { between the two } \\
\text { adjacent judgments }\end{array}$ & When compromise is needed \\
\hline Reciprocals & \multicolumn{2}{|c|}{$\begin{array}{l}\text { If activity } i \text { has one of the above numbers assigned to it when compared } \\
\text { to } j \text {, then } j \text { has the reciprocal value when compared with } i \text {. }\end{array}$} \\
\hline Rationals & $\begin{array}{l}\text { Ratios arising from the } \\
\text { scale }\end{array}$ & $\begin{array}{l}\text { If consistency were to be forced by obtaining } \mathrm{n} \\
\text { numerical values to span the matrix }\end{array}$ \\
\hline
\end{tabular}

Table 2. The fundamental scale (Saaty, 1977)

In order to evaluate the criteria matrix using the AHP method, the principal eigenvector must be calculated. Saaty (2003) justified that the eigenvector has two meanings: first, is a numerical ranking of the alternatives, and second, the ordering should also reflect intensity as indicated by the ratios of the numerical values. The explanation of why the eigenvector should be used (Saaty, 2003; Saaty, 1977) as well how to calculate it (Saaty 2000) can be found in the respective literature.

The criteria matrix should be then evaluated related to consistency, because, despite their best efforts, people's feelings and preferences remain inconsistent and intransitive (Saaty, 1977). Although the AHP approach permits some inconsistency, Saaty accept the judgments $\mathrm{w}$ if the consistency ratio (CR) is less than $10 \%$, where:

$$
\begin{gathered}
C R=\frac{C I}{R I} \\
C I=\frac{\lambda_{\text {max }}-n}{n-1}
\end{gathered}
$$

Where $n$ is the order of the considered matrix, and RI (random index) given by Saaty (2000) (Table 3).

\begin{tabular}{llllllllllllllll}
\hline $\mathbf{n}$ & 1 & 2 & 3 & 4 & 5 & 6 & 7 & 8 & 9 & 10 & 11 & 12 & 13 & 14 & 15 \\
\hline RI & 0 & 0 & 0,52 & 0,89 & 1,11 & 1,25 & 1,35 & 1,40 & 1,45 & 1,49 & 1,51 & 1,54 & 1,56 & 1,57 & 1,58 \\
\hline
\end{tabular}

Table 3. Random index (Saaty, 2000) 
After evaluating the criteria matrix, the alternatives must be analysed, through the use of matrixes and calculations of the principal eigenvector, which, in turn, is a Column Matrix. For each criterion, a matrix similar to Fig. 1 must be built, but comparing all the alternatives, following the same weight considerations presented in Table 2. Consequently, $n+1$ matrices should be created, where $n$ is the number of criteria - one criteria matrix and one matrix of the alternatives for each criterion. So, $n$ eigenvectors are obtained from $n$ alternative matrices (Column Matrix), which are combined into a new $n \times n$ matrix. This last matrix is then multiplied by the eigenvector of the criteria matrix. The final ranking of the alternatives results from this multiplication.

\section{b) Application}

Using the initial data of the attributes of RP processes presented in Table 1 and the relative importance of criteria in Scenario 1 and Scenario 2 described above, a decision maker is able to execute a process selection using AHP. The first step is to convert the qualitative and quantitative inputs from Table 1 into the fundamental scale of Saaty. Second, the criteria data (weights) must be also converted in the AHP matrix-format to calculate the local eigenvector.

In order to convert the qualitative analysis of cost (C) and build time (B) into numerical values, the results of the machines were compared pairwise to each other in a criteria matrix, and the eigenvector calculated to define local priorities. For this, initially, the 9 linguistic terms - very very low, very low, ..medium... very high, very very high - from Byun and Lee (2005) were converted into the numbers 1 through 9. So, a matrix of combinations could be built as the Table 4 . Then, for each criteria ( $\mathrm{C}$ and $\mathrm{B}$ ), a matrix was built comparing the attributes of each one of the six processes to each other to convert into numbers. The linguistic relations obtained were then compared to Table 4 to extract the respective numerical weight. The matrix created for the cost criterion (C) is presented as example (Table 3). This procedure intends to be closer to the original AHP approach due the pairwise comparison, instead of converting the linguistic terms directly into a scale to normalize them.

\begin{tabular}{|c|c|c|c|c|c|c|c|c|c|}
\hline & 1 & 2 & 3 & 4 & 5 & 6 & 7 & 8 & 9 \\
\hline & $\begin{array}{l}\text { Very } \\
\text { very } \\
\text { Slow }\end{array}$ & $\begin{array}{l}\text { Very } \\
\text { low }\end{array}$ & Low & $\begin{array}{c}\text { Slightly } \\
\text { low }\end{array}$ & Medium & $\begin{array}{l}\text { Slightly } \\
\text { high }\end{array}$ & High & $\begin{array}{l}\text { very } \\
\text { high }\end{array}$ & $\begin{array}{l}\text { very } \\
\text { very } \\
\text { high }\end{array}$ \\
\hline 1 Very very slow & 1 & 2 & 3 & 4 & 5 & 6 & 7 & 8 & 9 \\
\hline $2 \quad$ very low & $1 / 2$ & 1 & $11 / 2$ & 2 & $2 \frac{1}{2}$ & 3 & $31 / 2$ & 4 & $41 / 2$ \\
\hline low & $1 / 3$ & $2 / 3$ & 1 & $11 / 3$ & $12 / 3$ & 2 & $21 / 3$ & $22 / 3$ & 3 \\
\hline slightly low & $1 / 4$ & $1 / 2$ & $3 / 4$ & 1 & $1 \frac{1 / 4}{4}$ & $11 / 2$ & $13 / 4$ & 2 & $21 / 4$ \\
\hline Medium & $1 / 5$ & $2 / 5$ & $3 / 5$ & $4 / 5$ & 1 & $11 / 5$ & $12 / 5$ & $13 / 5$ & $14 / 5$ \\
\hline slightly high & $1 / 6$ & $1 / 3$ & $1 / 2$ & $2 / 3$ & $5 / 6$ & 1 & $11 / 6$ & $11 / 3$ & $11 / 2$ \\
\hline high & $1 / 7$ & $2 / 7$ & $3 / 7$ & $4 / 7$ & $5 / 7$ & $6 / 7$ & 1 & $11 / 7$ & $12 / 7$ \\
\hline $8 \quad$ very high & $1 / 8$ & $1 / 4$ & $3 / 8$ & $1 / 2$ & $5 / 8$ & $3 / 4$ & $7 / 8$ & 1 & $11 / 8$ \\
\hline 9 very very high & $1 / 9$ & $2 / 9$ & $1 / 3$ & $4 / 9$ & $5 / 9$ & $2 / 3$ & $7 / 9$ & $8 / 9$ & 1 \\
\hline
\end{tabular}

Table 4. Pairwise relation between the linguistic terms

The eigenvector obtained from the cost $(\mathrm{C})$ and build time (B) matrixes were employed to build the respective columns to the converted attributes matrix. The numerical values of 
accuracy (A) and surface roughness (R) were inverted before they were normalized because they are not beneficial values, i. e., lower values are desirable. The values of tensile strength (S) and elongation (E), where higher values are desirable, are simply normalized. Finally, the attributes matrix is built (Table 6).

\begin{tabular}{|c|c|c|c|c|c|c|c|}
\hline & Process1 & Process2 & Process 3 & Process4 & Process5 & Process6 & Eigenvector \\
\hline Process1 & 1,0000 & 1,0000 & 0,8750 & 0,7500 & 1,0000 & 0,1250 & 0,0742 \\
\hline Process2 & 1,0000 & 1,0000 & 0,8750 & 0,7500 & 1,0000 & 0,1250 & 0,0742 \\
\hline Process3 & 1,1429 & 1,1429 & 1,0000 & 0,8571 & 1,1429 & 0,1429 & 0,0848 \\
\hline Process 4 & 1,3333 & 1,3333 & 1,1667 & 1,0000 & 1,3333 & 0,1667 & 0,0989 \\
\hline Process5 & 1,0000 & 1,0000 & 0,8750 & 0,7500 & 1,0000 & 0,1250 & 0,0742 \\
\hline Process6 & 8,0000 & 8,0000 & 7,0000 & 6,0000 & 8,0000 & 1,0000 & 0,5936 \\
\hline & & & & & \multicolumn{3}{|c|}{$\lambda \max =6,0000 ; C I=0,0000 ; C R=0,0000$} \\
\hline
\end{tabular}

Table 5. Cost criterion matrix

\begin{tabular}{ccccccc}
\hline & $\mathrm{A}$ & $\mathrm{R}$ & $\mathrm{S}$ & $\mathrm{E}$ & $\mathrm{C}$ & $\mathrm{B}$ \\
\hline Process1 & 0,2053 & 0,2257 & 0,3333 & 0,1235 & 0,0742 & 0,1311 \\
Process2 & 0,1642 & 0,1174 & 0,2051 & 0,2099 & 0,0742 & 0,1311 \\
Process3 & 0,1971 & 0,0699 & 0,1538 & 0,2469 & 0,0848 & 0,0820 \\
Process4 & 0,1331 & 0,0733 & 0,1282 & 0,2469 & 0,0989 & 0,1639 \\
Process5 & 0,2593 & 0,4191 & 0,1538 & 0,1481 & 0,0742 & 0,1639 \\
Process6 & 0,0411 & 0,0946 & 0,0256 & 0,0247 & 0,5936 & 0,3279 \\
\hline
\end{tabular}

Table 6. Attributes matrix to AHP approach

After evaluating the attributes matrix, the information about criteria (Scenario 1 and Scenario 2) and their weights have to be converted into AHP form. It is therefore necessary, for each scenario, to produce the criteria matrix and to calculate the eigenvector. As an example, a decision maker would define the weights and calculate the eigenvector as presented in Table 7. One should note that the judgments applied to scenario 2 matrix are not consistent, however, the inconsistency is at a low level $(\mathrm{CR}<0,1)$ and therefore the matrix may be used.

One should notice that the process capabilities were intentionally not reproduced here. The processes evaluation itself is a hard work, due to constant new development of materials and machines. Best results of process selection are obtained with up-to-date process analysis.

\subsubsection{Multiplicative AHP (MAHP)}

\section{a) Method}

The Multiplicative Analytic Hierarchy Process (MAHP) was developed by Prof. Freeek Lootsma in 1990, and is based on AHP, but uses another scale as well as another algorithm to define the priorities (Eguti et al.,2007). In practice, MAHP has the characteristic to moderate the valuation of "extreme" versus "balanced" alternatives and is less susceptible to rank reversal when adding or removing alternatives (Stam and Silva, 2003).

The MAHP process has the same hierarchy as the AHP. In order to define the relative weight between attributes and criteria, the MAHP uses another scale, as represented in 
Table 9. As done to AHP, the MAHP requires one matrix for the alternative attributes and $n$ matrixes for the $n$ criteria.

\begin{tabular}{cc}
$\begin{array}{c}\text { Scenario } 1 \text { - cost of the part }(\mathrm{C}) \text { and build } \\
\text { time }(\mathrm{B}) \text { considered more important }\end{array}$ & $\begin{array}{c}\text { Scenario } 2 \text { - accuracy }(\mathrm{A}) \text { and surface } \\
\text { roughness }(\mathrm{R}) \text { considered more important }\end{array}$ \\
\hline
\end{tabular}

\begin{tabular}{|c|c|c|c|c|c|c|c|c|c|c|c|c|c|c|c|}
\hline & A & $\mathrm{R}$ & S & $E$ & C & B & $\begin{array}{c}\text { eigenvect } \\
\text { or }\end{array}$ & & A & $\mathrm{R}$ & $S$ & $E$ & C & B & $\begin{array}{c}\text { eigenvect } \\
\text { or }\end{array}$ \\
\hline & 1 & 1 & 3 & 3 & $1 /$ & $1 /$ & 0,1113 & A & 1 & 1 & 3 & 3 & 5 & 5 & 0,3253 \\
\hline A & & & & & & 5 & & $\mathrm{R}$ & 1 & 1 & 3 & 3 & 5 & 5 & 0,3253 \\
\hline $\mathrm{R}$ & 1 & 1 & 3 & 3 & $\begin{array}{c}1 / \\
5 \\
\end{array}$ & $\begin{array}{c}/ \\
5 \\
\end{array}$ & 0,1113 & $S$ & $\begin{array}{l}1 / \\
3\end{array}$ & $\begin{array}{c}1 / \\
3\end{array}$ & 1 & 1 & 3 & 3 & 0,1113 \\
\hline$S$ & $\begin{array}{c}/ \\
3 \\
\end{array}$ & $\begin{array}{c}1 / \\
3 \\
\end{array}$ & 1 & 1 & $\begin{array}{c}1 / \\
3\end{array}$ & $\begin{array}{c}1 / \\
3\end{array}$ & 0,0634 & $\mathrm{E}$ & $\begin{array}{c}1 / \\
3\end{array}$ & $\begin{array}{c}1 / \\
3\end{array}$ & 1 & 1 & 3 & 3 & 0,1113 \\
\hline E & $\begin{array}{c}1 / \\
3\end{array}$ & $\begin{array}{c}1 / \\
3 \\
\end{array}$ & 1 & 1 & $\begin{array}{c}1 / \\
3\end{array}$ & $\begin{array}{c}1 / \\
3 \\
\end{array}$ & 0,0634 & C & $\begin{array}{l}1 / \\
5\end{array}$ & 1/ & $\begin{array}{c}1 / \\
1 / \\
3\end{array}$ & $\begin{array}{c}1 / \\
1 / \\
3\end{array}$ & 1 & 1 & 0,0634 \\
\hline $\mathrm{C}$ & 5 & 5 & 3 & 3 & 1 & 1 & 0,3253 & & $1 /$ & $1 /$ & $1 /$ & $1 /$ & & & 0,0634 \\
\hline $\mathrm{B}$ & 5 & 5 & 3 & 3 & 1 & 1 & 0,3253 & B & 5 & 5 & 3 & 3 & 1 & 1 & \\
\hline \multicolumn{8}{|c|}{$\lambda_{\max }=6,589 ; \mathrm{CI}=0,118 ; \mathrm{CR}=0,09$} & \multicolumn{8}{|c|}{$\lambda_{\max }=6,589 ; \mathrm{CI}=0,118 ; \mathrm{CR}=0,09$} \\
\hline
\end{tabular}

Table 7. Criteria matrix to AHP approach (adapted from [Byun and Lee, 2005])

The multiplication of the attributes matrix (Table 6) by the eigenvector of each scenario (Table 7) results in the final ranking.

\begin{tabular}{|c|c|c|c|c|c|}
\hline \multicolumn{3}{|c|}{ scenario 1} & \multicolumn{3}{|c|}{ scenario 2} \\
\hline Process & Priority & $\%$ & Process & Priority & $\%$ \\
\hline Process6 & 0,3181 & $31,81 \%$ & Process 5 & 0,2694 & $26,94 \%$ \\
\hline Process5 & 0,1721 & $17,21 \%$ & Process1 & 0,2041 & $20,41 \%$ \\
\hline Process1 & 0,1437 & $14,37 \%$ & Process 2 & 0,1508 & $15,08 \%$ \\
\hline Process4 & 0,1322 & $13,22 \%$ & Process3 & 0,1420 & $14,20 \%$ \\
\hline Process 2 & 0,1244 & $12,44 \%$ & Process4 & 0,1256 & $12,56 \%$ \\
\hline Process3 & 0,1094 & $10,94 \%$ & Process6 & 0,1082 & $10,82 \%$ \\
\hline
\end{tabular}

Table 8. AHP final ranking

The evaluation of the matrixes is done as explained by Eguti et al.(2007). For each matrix, the weights are transformed into new values, calculated by (4), where $\delta i j$ is an integer-valued index designating the decision maker's judgments (Table 9), and $\gamma$ is a scale parameter. A plausible value for the scale parameter is given by $\ln 2$, which implies on a geometric scale with progression factor 2 (Lootsma, 1996).

$$
a_{i j}=e^{\gamma \delta i j}
$$




\begin{tabular}{c|cc}
\hline Judgements & MAHP $\left(\boldsymbol{\delta}_{i j}\right)$ & AHP $\left(\mathbf{w}_{\mathfrak{i}} / \mathbf{w}_{\mathbf{j}}\right)$ \\
\hline Very strong preference for $\mathrm{w}_{\mathrm{j}}$ versus $\mathrm{w}_{\mathrm{i}}$ & -8 & $1 / 9$ \\
\hline Strong preference for $\mathrm{w}_{\mathrm{j}}$ versus $\mathrm{w}_{\mathrm{i}}$ & -6 & $1 / 7$ \\
\hline Definite preference for $\mathrm{w}_{\mathrm{j}}$ versus $\mathrm{w}_{\mathrm{i}}$ & -4 & $1 / 5$ \\
\hline Weak preference for $\mathrm{w}_{\mathrm{j}}$ versus $\mathrm{w}_{\mathrm{i}}$ & -2 & $1 / 3$ \\
\hline Indifference preference for $\mathrm{w}_{\mathrm{i}}$ versus $\mathrm{w}_{\mathrm{j}}$ & 0 & 3 \\
\hline Weak preference for $\mathrm{w}_{\mathrm{i}}$ versus $\mathrm{w}_{\mathrm{j}}$ & +2 & 5 \\
\hline Definite preference for $\mathrm{w}_{\mathrm{i}}$ versus $\mathrm{w}_{\mathrm{j}}$ & +4 & 7 \\
\hline Strong preference for $\mathrm{w}_{\mathrm{i}}$ versus $\mathrm{w}_{\mathrm{j}}$ & +6 & 9 \\
\hline Very strong preference for $\mathrm{w}_{\mathrm{i}}$ versus $\mathrm{w}_{\mathrm{j}}$ & +8 & \\
\hline
\end{tabular}

Table 9. Comparison between relative weight scales from AHP to MAHP

$$
c_{i}=\frac{1}{n} \sum_{j=1}^{n} a_{i j} \mathrm{i}=1,2, \ldots \mathrm{n}
$$

Following, the weights of criteria and attributes matrixes must be calculated. These values are the arithmetical mean, as shown by the equations (5) and (6), respectively.

$$
\begin{gathered}
A_{i k}=\frac{1}{m} \sum_{j=1}^{m} a_{i j} \mathrm{i}=1,2, \ldots \mathrm{m} ; \mathrm{k}=1,2, \ldots \mathrm{n} \\
P_{i}=\prod_{j=1}^{n}\left(A_{i j}\right)^{c_{j}} \mathrm{i}=1,2, \ldots \mathrm{m}
\end{gathered}
$$

Where $m$ is the number of alternatives and $n$ the number of criteria. The last step of the MAHP is to obtain the decision vector, using (7).

\section{b) Application}

In order to apply the MAHP, the matrixes used for AHP were directly converted using the scale conversion in Table 9 and following the calculations described before. The converted matrixes as well as their respective priority vectors are presented in Table 10.

\begin{tabular}{c|c|c|c|c|c|c|c|c|c|c|c|c|c|c|c|c|}
\hline \multicolumn{10}{c}{ scenario 1 } \\
\hline & A & R & S & E & C & B & priority \\
\hline A & 0 & 0 & 2 & 2 & -4 & -4 & 0,0914 \\
\hline R & 0 & 0 & 2 & 2 & -4 & -4 & 0,0914 \\
\hline S & -2 & -2 & 0 & 0 & -2 & -2 & 0,0521 \\
\hline E & -2 & -2 & 0 & 0 & -2 & -2 & 0,0521 \\
\hline C & 4 & 4 & 2 & 2 & 0 & 0 & 0,3566 \\
\hline B & 4 & 4 & 2 & 2 & 0 & 0 & 0,3566 \\
\hline
\end{tabular}

Table 10. Input matrices for MAHP (Converted from AHP notation)

The calculations of the attributes matrix were carried out as for the AHP. The quantitative attributes had their values inverted (only A and R) and normalized. Relating both 
qualitative attributes, one matrix was built to each criterion, in which each alternative was compared to each other, as done for AHP. The conversion from linguistic terms to numerical values was done with a table similar to Table 4, with the respective MAHP values instead of the AHP scale. Following, these matrixes were submitted to the MAHP process to evaluate the local priorities. As a result, the matrix presented here was obtained as the attribute matrix for the MAHP approach.

\begin{tabular}{ccccccc}
\hline & $\mathrm{A}$ & $\mathrm{R}$ & $\mathrm{S}$ & $\mathrm{E}$ & $\mathrm{C}$ & $\mathrm{B}$ \\
\hline Process1 & 0,20526 & 0,22568 & 0,33333 & 0,12346 & 0,00698 & 0,06985 \\
Process2 & 0,16421 & 0,11735 & 0,20513 & 0,20988 & 0,00698 & 0,06985 \\
Process3 & 0,19705 & 0,06985 & 0,15385 & 0,24691 & 0,01405 & 0,00855 \\
Process4 & 0,13314 & 0,07335 & 0,12821 & 0,24691 & 0,02829 & 0,14066 \\
Process5 & 0,25928 & 0,41912 & 0,15385 & 0,14815 & 0,00698 & 0,14066 \\
Process6 & 0,04105 & 0,09464 & 0,02564 & 0,02469 & 0,93674 & 0,57042 \\
\hline
\end{tabular}

Table 11. Attribute's matrix of MAHP

The final evaluation of the MAHP is obtained by multiplying the attribute's matrix by the priority vector of each scenario (Table 10). The results obtained with MAHP for the input data from both previous works are presented and compared in the Table 12.

\begin{tabular}{|c|c|c|c|c|c|}
\hline \multicolumn{3}{|c|}{ scenario 1} & \multicolumn{3}{|c|}{ scenario 2} \\
\hline Process & Priority & $\%$ & Process & Priority & $\%$ \\
\hline Process6 & 0,5525 & $55,2 \%$ & Process5 & 0,2914 & $29,1 \%$ \\
\hline Process5 & 0,1303 & $13,0 \%$ & Process1 & 0,2097 & $21,0 \%$ \\
\hline Process4 & 0,0986 & $9,9 \%$ & Process2 & 0,1486 & $14,9 \%$ \\
\hline Process1 & 0,0905 & $9,1 \%$ & Process3 & 0,1404 & $14,0 \%$ \\
\hline Process2 & 0,0747 & $7,5 \%$ & Process4 & 0,1183 & $11,8 \%$ \\
\hline Process3 & 0,0533 & $5,3 \%$ & Process6 & 0,0917 & $9,2 \%$ \\
\hline
\end{tabular}

Table 12. MAHP final ranking

\subsubsection{VDI guidelines}

The Association of German Engineers (VDI - Verein Deutscher Engenieure) edits regularly guidelines to support engineers to their habitual activities. These guidelines oft support or even become standards. Two VDI guidelines are here considered: The VDI 3404 (2007) and the VDI 2225 (1998).

The VDI 3404 presents, besides definitions regarding layer-manufacturing processes, a simplified method to select processes. It presents generically prototypes criteria and compares them with most significant characteristics of several RP process can offer. The proposed process selection defines some general characteristics of different kind of parts (from visual analysis prototypes up to final products) as well as process properties. However, these definitions are freezed in time. One should consider new process developments offered by additive manufacturing systems suppliers and its own parts requirements. 
A pragmatic view of a RP system selection is the assumption that it is a selection procedure inside of the product development process. Pahl et. al. (2006) presented approaches to evaluate decisions during the product development process. Since Rapid Prototyping system selection is a typical application of product development, the guidelines proposed by VDI 2225 are evaluated here.

\section{a) Method}

A selection procedure presented by Pahl et. al. (2006) is based on the VDI 2225 (1998), a guideline instruction edited by the Association of German Engineers (VDI). This guideline proposes a simple approach, based on a five-points scale to score the alternatives. The scale and the evaluation table are presented in Table 13Error! Reference source not found.

\begin{tabular}{cc}
\hline \multicolumn{2}{c}{ Score scale } \\
Description & Score \\
\hline Very good & 4 \\
Good & 3 \\
Satisfactory & 2 \\
Acceptable & 1 \\
Unsatisfactory & 0 \\
\hline
\end{tabular}

\begin{tabular}{cccc}
\hline Technical feature & Alternative A & Alternative $\mathrm{t}$ & Ideal \\
\hline Criterion 1 & $\mathrm{Wa} 1$ & $\mathrm{Wt} 1$ & 4 \\
Criterion 2 & $\mathrm{Wa} 2$ & $\mathrm{Wt} 2$ & 4 \\
$\ldots$ & $\ldots$ & $\ldots$ &.. \\
Criterion $\mathrm{n}$ & $\mathrm{W}_{\mathrm{an}}$ & $\mathrm{W}_{\mathrm{tn}}$ & 4 \\
\hline Sum & $\Sigma \mathrm{Wa}$ & $\Sigma \mathrm{W}_{\mathrm{t}}$ & $4 . \mathrm{n}$ \\
Technical value $\mathrm{x}$ & $\Sigma \mathrm{W}_{\mathrm{a}} / 4 . \mathrm{n}$ & $\Sigma \mathrm{W}_{\mathrm{t}} / 4 . \mathrm{n}$ & 1 \\
Economical value $\mathrm{y}$ & $\mathrm{H}_{\mathrm{i}} / \mathrm{H}_{\mathrm{a}}$ & $\mathrm{H}_{\mathrm{i}} / \mathrm{H}_{\mathrm{t}}$ & 1 \\
\hline
\end{tabular}

Table 13. Scale and evaluation table of VDI 2225

Where $W_{t i}$ are the scores of the $i$ criterion given to the $\mathrm{t}$ alternative following the scale, $n$ the total number of criteria, $H_{i}$ the ideal manufacturing cost and the $H_{t}$ the manufacturing cost of the alternative $t . H_{i}$ can be estimated by $H_{i}=0,7 . H_{z u l}$, where $H_{z u l}$ is the permissible manufacturing cost, which is to be determined considering, for example, the lowest price of concurrent products and the revenue margin of the alternative. Some instructions can be found in the literature to predict the cost of each alternative.

VDI 2225 (1998) also considers that the criteria may have different weights. In this case, the technical value should be calculated by (8). Although, VDI do not specify or recommend the scale to weight the alternatives.

$$
x=\frac{\sum g_{i} \cdot w_{t i}}{4 . \sum g_{i}}
$$

Where $g_{i}$ is the weight of the criterion $i$.

It is to observe that the computation of costs is done separately by this approach. It is expressed in terms of the economical value $y$. Further, the VDI 2225 proposes a graphic approach to evaluate the alternative, plotting the technical value $x$ versus the economical value $y$, defining a point $s$, in the s-diagram (graph $x$ versus $y$ ). VDI suggested that the best solutions have a balanced relationship between cost and technical skills, thus, being nearly the diagonal (traced) line of the s-diagram (Fig. 3).

The s-diagram is also useful to accomplish the evolution of a product. The values $s 1, s 2$ and $s 3$ could represent respectively the first, second and third edition of a product. Pahl et. al. (2006) recommends the hyperbole-technique to evaluate the total weight of each alternative, $W$, by (9). 


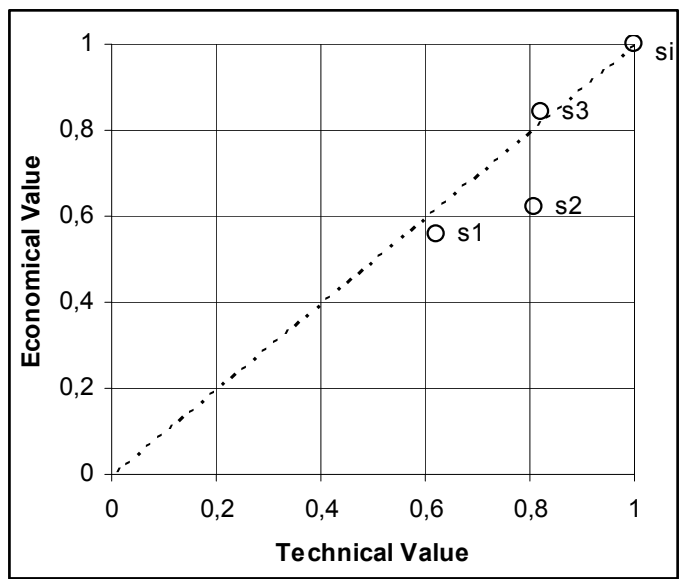

Fig. 3. S-diagram example (VDI 2225, 1998)

$$
W=\sqrt{(x \cdot y)}
$$

\section{b) Application}

In order to apply the guidelines from VDI 2225, the alternative matrix and criteria matrix have to be converted into the VDI scale and form (Table 13). The conversion table of alternatives to VDI notation is present in Table 14.

\begin{tabular}{llllll}
\hline & A & R & S & E & B \\
\hline Process1 & 4 & 3 & 4 & 2 & 2 \\
Process2 & 4 & 2 & 2 & 3 & 2 \\
Process3 & 4 & 0 & 2 & 4 & 0 \\
Process4 & 3 & 0 & 1 & 4 & 2 \\
Process5 & 4 & 4 & 2 & 2 & 2 \\
Process6 & 0 & 1 & 0 & 0 & 4 \\
\hline
\end{tabular}

Table 14. Alternatives matrix following VDI scale

It is to note that attribute Costs (C) were intentionally removed from the Table 14, because VDI proposes a separate economical analysis. The numerical values of the alternatives attributes were mated to the VDI scale, matching the extremity of measured values and of the scale and uniformly distributing the intermediate values. For the attributes A, R and B, the highest values were matched to zero and the lowest to four, because they are unwanted attributes (the higher the value, the less desirable). The calculation of the attributes $\mathrm{S}$ and $\mathrm{E}$ were made matching the highest values to four, because higher values are desired.

After evaluating the attributes of the alternatives, the following step is to convert the criteria matrixes (the 2 scenarios) to extract the weights used in the VDI guideline. Because the matrixes presented by the previous works are not consistent, it is impossible to extract the exact weight relations among the criteria. Although, in order to compare the different approaches, the following matrices are assumed to be likely representative to the both scenarios (Table 15). One should note that the attribute cost (C) was here also removed. 


\begin{tabular}{ccc}
\hline & Scenario 1 & Scenario 2 \\
\hline A & 2 & 6 \\
R & 2 & 6 \\
S & 1 & 3 \\
E & 1 & 3 \\
B & 6 & 1 \\
\hline
\end{tabular}

Table 15. Scenario matrixes into VDI form

The data presented above is enough to perform the calculation of the technical value. The next step consists of calculating the economical value. Once again, some approximations have to be done to allow this estimation, because neither the real cost relation nor the acceptable value is presented.

Since the VDI guideline recommends the economical value to be the relation between the acceptable and the alternative costs, it was considered that the normalized values from the references to be used to represent this relation. VDI also recommends that the acceptable cost should be, if possible, estimated comparing similar products on the market, thus, it was assumed here as the acceptable cost $\left(H_{z u l}\right)$ being the lowest cost (value) among the normalized alternatives values.

\begin{tabular}{|c|c|c|c|c|c|c|c|c|c|c|c|c|c|c|c|}
\hline \multirow{2}{*}{ 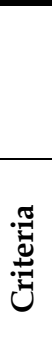 } & \multirow{2}{*}{ 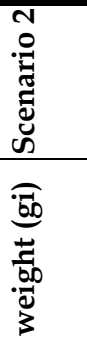 } & \multicolumn{2}{|c|}{ 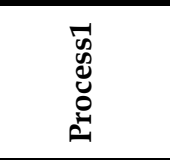 } & \multicolumn{2}{|c|}{ 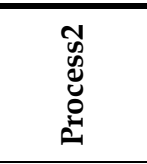 } & \multicolumn{2}{|c|}{ 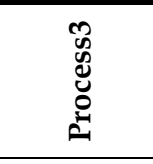 } & \multicolumn{2}{|c|}{ 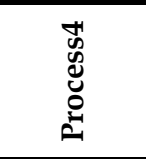 } & \multicolumn{2}{|c|}{ 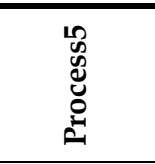 } & \multicolumn{2}{|c|}{ 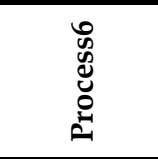 } & \multicolumn{2}{|c|}{ 胥 } \\
\hline & & 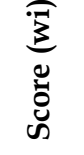 & 苑 & 3 & 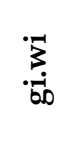 & 3 & 感 & 3 & 家 & 3 & م-30 & 3 & 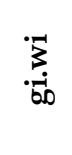 & 3 & 递 \\
\hline A & 6 & 4 & 24 & 4 & 24 & 4 & 24 & 3 & 18 & 4 & 24 & 0 & 0 & 4 & 24 \\
\hline $\mathrm{R}$ & 6 & 3 & 18 & 2 & 12 & 0 & 0 & 0 & 0 & 4 & 24 & 1 & 6 & 4 & 24 \\
\hline$S$ & 3 & 4 & 12 & 2 & 6 & 2 & 6 & 1 & 3 & 2 & 6 & 0 & 0 & 4 & 12 \\
\hline $\mathrm{E}$ & 3 & 2 & 6 & 3 & 9 & 4 & 12 & 4 & 12 & 2 & 6 & 0 & 0 & 4 & 12 \\
\hline B & 1 & 2 & 2 & 2 & 2 & 0 & 0 & 2 & 2 & 2 & 2 & 4 & 4 & 4 & 4 \\
\hline & $\begin{array}{l}\text { hical } \\
\text { ue }\end{array}$ & & 0,82 & & 0,70 & & 0,55 & & 0,46 & & 0,82 & & 0,13 & & 1 \\
\hline & $\begin{array}{l}\text { lized } \\
\text { st }\end{array}$ & 1,00 & & 1,00 & & 0,89 & & 0,79 & & 1,00 & & 0,06 & & & \\
\hline & $\begin{array}{l}\text { mical } \\
\text { de }\end{array}$ & & 0,04 & & 0,04 & & 0,05 & & 0,05 & & 0,04 & & 0,70 & & \\
\hline
\end{tabular}

Table 16. VDI 2225 evaluation table for Scenario 2

Table 16 presents the results of scenario 2 following the VDI notation. The Fig. 4 represents the evaluation of the W (as (9)) for both scenarios. One should note that due to the separate cost evaluation proposed by VDI, the relative weight of cost compared to the others attributes can not be done. Although, it is to note that the cost has the same weight than all 
other attributes together, which makes the relative weight of the attributes cost always very high. This can be observed in the Fig. 4, scenario 2, where the accuracy and surface roughness are to be more important, and the process with a lower cost was also the first option.

One should notice that due to the separate cost evaluation proposed by VDI, the relative weight of cost compared to the others attributes can not be done. Although, it is also important that the cost has the same weight than all other attributes together, which makes the relative weight of the attributes cost always very high. This can be observed in the Fig. 4, scenario 2, where the accuracy and surface roughness are to be more important, and the process with a lower cost was also the first option.
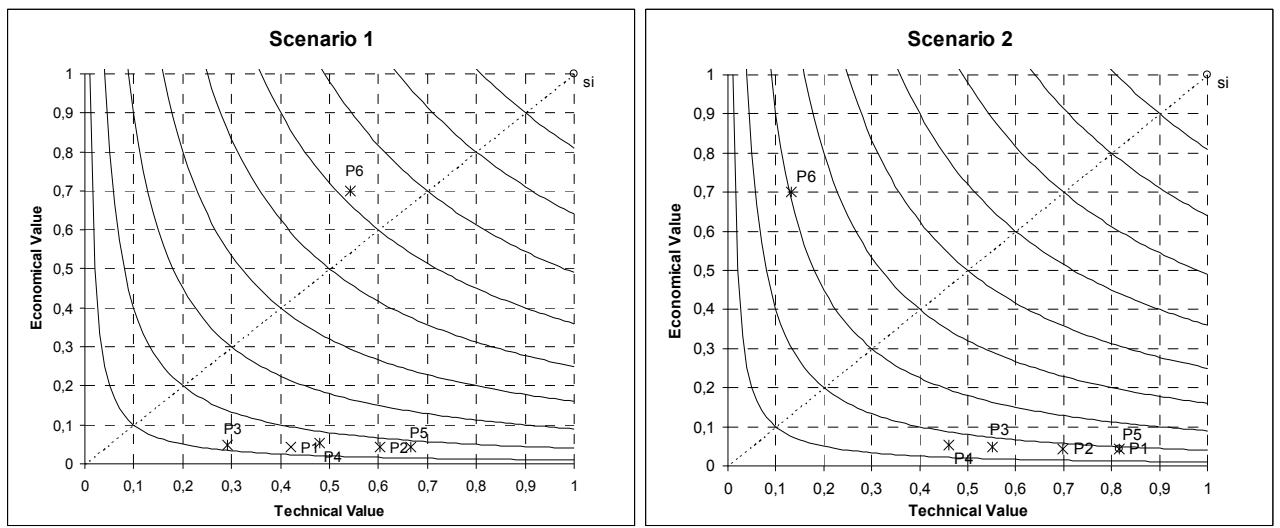

Fig. 4. VDI 2225 graphic results for Scenario 1 and Scenario 2

\section{Part II: Rapid manufacturing application}

The main advantages of additive manufacturing technologies (AMT) are related to the ability to build geometrically complex shapes without tooling and with high process automation. These characteristics are very useful when producing prototypes, but they can be even more advantageous for final products, if AMT can be integrated into product development. It is because final products may allow the designers and engineers to improve part functionality using more complex shapes. Prototypes have usually a defined form, which may not be modified.

However, some conditions are necessary in order to use AMT for final parts. These conditions are related to lot sizes, shape complexity and costs - AMT are still expensive manufacturing processes. At small lot sizes, such as with customized products, traditional manufacturing technologies become expensive due to high costs of required tooling. Small lot sizes and complex shaped parts are typical features encountered in the aircraft industry. This chapter presents a decision support method based on processes technological information concerning Rapid Manufacturing of plastic parts for aircraft cabin interiors. Nowadays, two RP Technologies are able to process plastic materials, which comply flammability requirements: Fused Deposition Modeling (FDM) and Selective Laser Sintering (SLS). A method is presented to consider the possible advantages and restrictions when considering the manufacturing process. Further, a procedure to evaluate quality, production 
time and cost is presented. The method is illustrated with examples on the selection of manufacturing technology to produce a customized decoration part and an air duct. Typical costs and manufacturing time of injection moulding processes were also compared and analyzed with the proposed method. It is possible to define the break-even point, when conventional processes become preferred then AMT. Fig. 5 illustrates the general process selection presented in this work.

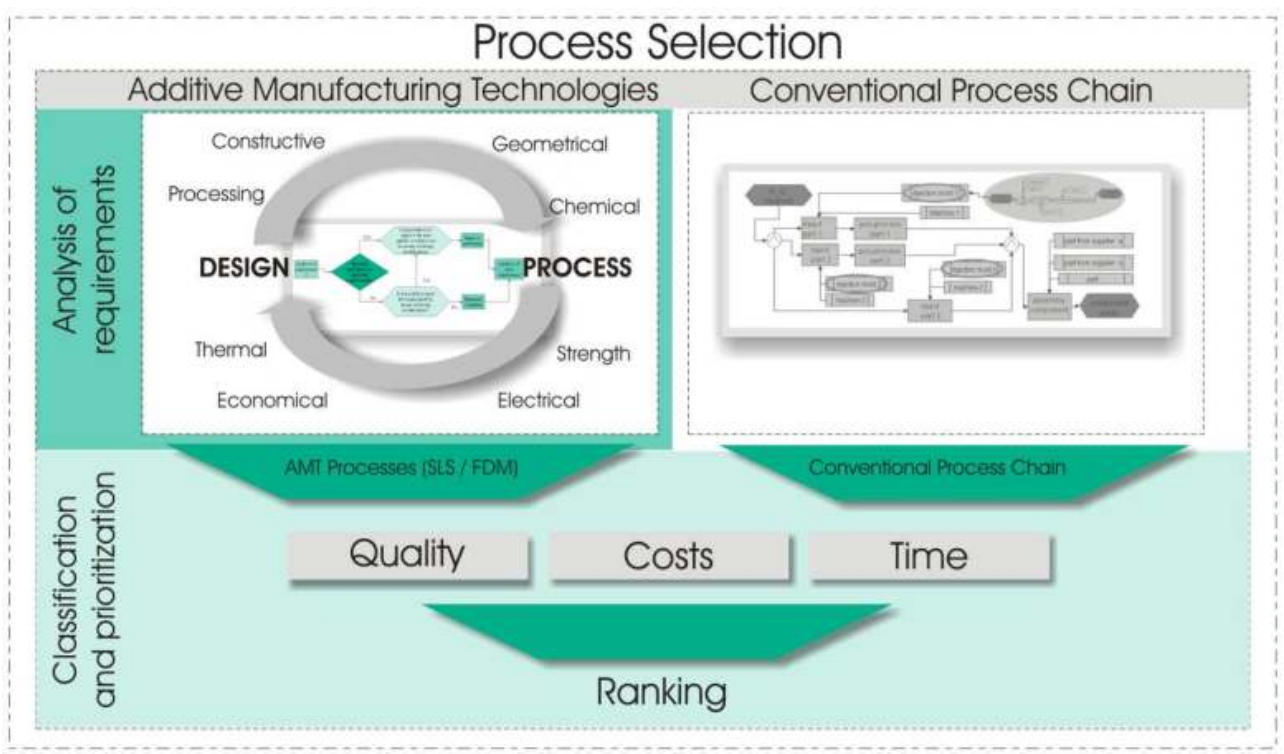

Fig. 5. Material restriction when considering RT in the aircraft industry

Fig. 5 presents also the parallel comparison with a conventional process chain. Since all parts are so far designed to be produced by processes other then AMT (called here conventional processes), there is always an alternative process chain. It has, in turn, been optimized over years, and the costs, quality and delivery time quite known by manufacturing engineers. It is not the aim of this work to select the conventional alternative, but, typical delivery time and costs related to the both examples will be presented later in this chapter.

The proposed procedure to evaluate AMT is divided into two phases: 1) analysis of requirements; and 2) classification and prioritization, as explained in the next sections.

\subsection{Analysis of requirements}

Analysis of requirements aims to eliminate processes - or process chains - which do not provide adequate properties. It begins with the material analysis. Grimm (2004) argues that material selection may lead to a manageable quantity of process to analyze. Thus, it should be performed first.

The Association of German Engineers (VDI), in the outline of guideline VDI 3404 (2007), presents generically parts requirements (Table 17). Decision makers should use it as check list when summarizing their parts requirement. The quality of a part is also related to how its function is performed. Thus, AMT must assure these requirements. Each specific 
requirement should be analyzed based on process information (process attributes) found in literature, but even more important, based on up-to-date analyses. They could be obtained directly at manufacturers and resellers, but they are usually not specific enough. The tensile strength is an example, where the manufacturer information does not specify the material resistance among different building directions. Alternatively, attributes or rule databases (Masood and Soo, 2002; Katschka, 1999) could be used, but with restrictions. Furthermore, a large amount of work would be needed to maintain such databases up to date. The process attributes used in this work were available in the literature (Borille, 2009).

\begin{tabular}{|c|c|}
\hline Requirements & Relevant quality characteristics \\
\hline $\begin{array}{l}\text { Constructive } \\
\text { requirements }\end{array}$ & Size, scale, weight, density, textures, colors / transparency, odor \\
\hline $\begin{array}{l}\text { Geometrical } \\
\text { requirements }\end{array}$ & $\begin{array}{c}\text { Component size and complexity, length and angle dimensions, dimensional } \\
\text { tolerances, form and position deviations, shrinkage, minimal structures, } \\
\text { walls, layer thicknesses }\end{array}$ \\
\hline $\begin{array}{l}\text { Processing } \\
\text { requirements }\end{array}$ & $\begin{array}{c}\text { Machinability, formability, joinability, Surface finishing (painting, coating, } \\
\text { polishing) }\end{array}$ \\
\hline $\begin{array}{l}\text { Strength } \\
\text { requirements }\end{array}$ & $\begin{array}{l}\text { Tensile, compression, bending and torsion strength, static and dynamic } \\
\text { creep rupture strength, impact strength, hardness, friction coefficient, } \\
\text { abrasion }\end{array}$ \\
\hline $\begin{array}{l}\text { Thermal } \\
\text { requirements }\end{array}$ & $\begin{array}{l}\text { Use temperature ranges, resistance to heat, softening temperature, specific } \\
\text { heat, thermal conductivity, thermal expansion coefficient }\end{array}$ \\
\hline $\begin{array}{l}\text { Electrical } \\
\text { requirements }\end{array}$ & $\begin{array}{l}\text { Dielectric strength, surface and spec. Contact resistance, dielectric property } \\
\text { values, tracking resistance }\end{array}$ \\
\hline $\begin{array}{l}\text { Chemical } \\
\text { requirements }\end{array}$ & $\begin{array}{l}\text { Flammability, toxicity, resistance to aggressive media, water absorption, } \\
\text { biocompatibility, light stability, light transmission }\end{array}$ \\
\hline $\begin{array}{l}\text { Economical } \\
\text { requirements }\end{array}$ & $\begin{array}{l}\text { Units/lot size, production times/delivery times, production costs, reliability, } \\
\text { waste and disposal costs }\end{array}$ \\
\hline
\end{tabular}

Table 17. Quality characteristics of part requirements (adapted from VDI3404, 2007)

In order to evaluate the requirements, the logical question associated to each one is if process and/or material meet the requirement. However, there are two further questions proposed: 1) if the requirement is not met is it possible to meet the requirement by means of design modifications? 2) Is it possible to improve the part quality or reduce cost by means of design modifications? Fig, 6 presents the sequential decision regarding the verification of a requirement.

This verification aims at inducing the decision maker to think about all the possibilities regarding AMT. Freedom of form and process flexibility should be always in mind when answering these questions. The potential of implementing AMT lies on the component improvement, which can be as weight reduction, reduction of parts quantity by assembling components, reducing costs of complex shapes among others.

Economical requirements, expressed by the cost, have two major functions in the proposed methods. First, in the initial procedure phase, the cost should be use as a filter to eliminate alternatives which are not at reasonable levels. The cost of each alternative will be needed later again, when creating the alternatives ranking, comparing with their quality and fabrication time. It should be interesting to create a database containing the considerations 
of each requirement (Design solutions). Applied design solutions could be based on the results from previous processes.

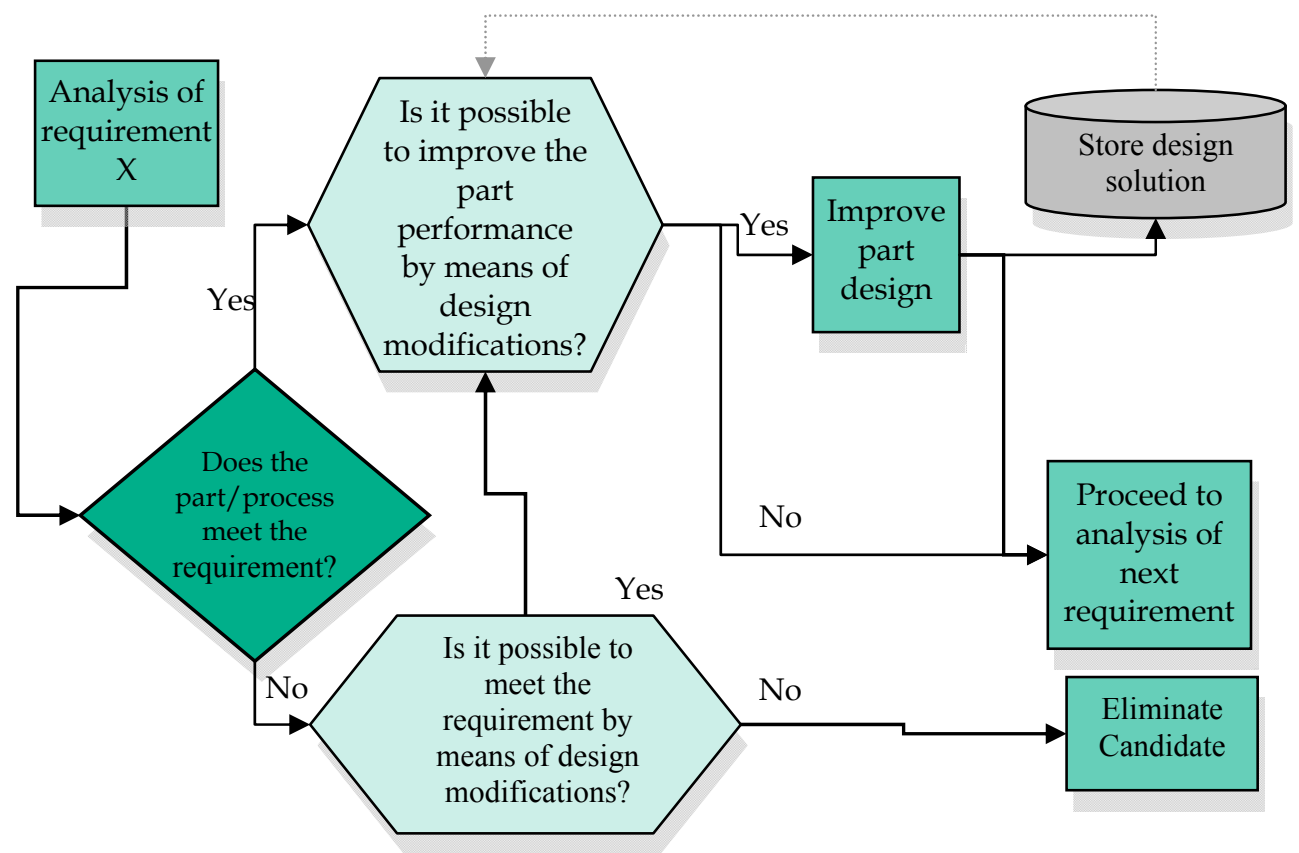

Fig. 6. Analysis of requirements

This procedure aims to evaluate whether an AMT process is able to provide adequate technical parts. It is a filtering procedure, but, it also aims to integrate product and process. There is a reason why not to classify the process (create a ranking) at this phase, as proposed in the literature (Rao and Padmanabhan, 2007; Rao, 2007). It is because the technical analysis is done separately from cost and time. Cost and time are usually associated to - low values, better values -, but most technical requirements can not be analyzed this way. It is difficult to argue that a part, which present surface roughness $R_{a}=2 \mu \mathrm{m}$, is five times better than other which has $10 \mu \mathrm{m}$, when the specification is $15 \mu \mathrm{m}$. It is correct to affirm that the both processes are good enough regarding this requirement. Even when scale normalization is used, the rates between requirements could still carry such inconsistencies.

Technical requirements act as filters, but they also carry information for the second phase. All the technical considerations should be stored under - Quality - and will be used to generate the final ranking - Classification and prioritization. Each relevant aspect observed when considering the requirements should be aggregated within - Quality.

In doing the analysis of requirements before observing the costs, it is expected that all improvement possibilities are checked and aggregated together. If the part improvement reaches a high level, it can be strong enough to be contrasted to cost. One frequent characteristic observed in industries when studying the possibilities to apply AMT, is the 
cost evaluation as first consideration. As the material costs are comparatively expensive, the technology is rejected.

\subsection{Classification and prioritization}

The second phase of the process selection is the ranking generation. It is proposed to use the Analytic Hierarchy Process (AHP) in order to evaluate the three major aspects: quality, cost and time. The general hierarchy of is expresses as in Fig. 7.

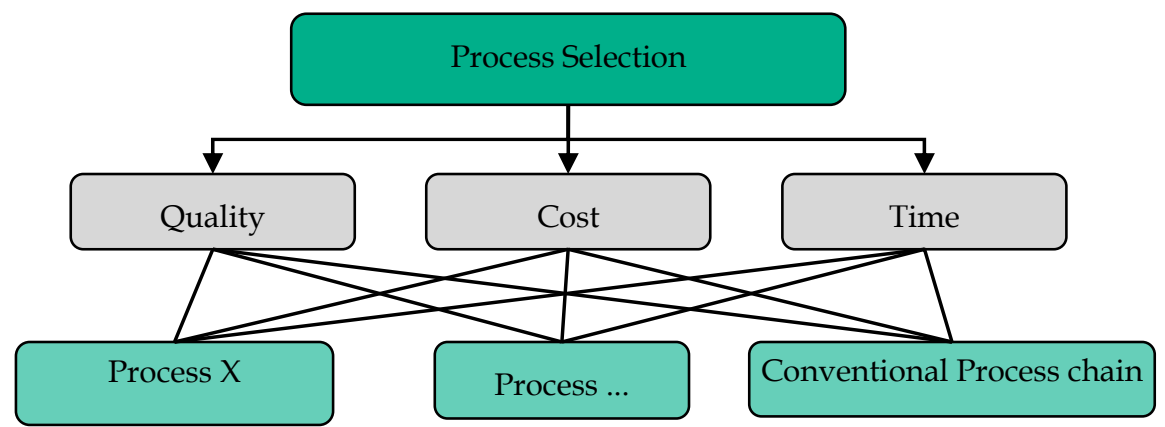

Fig. 7. The proposed hierarchical structure of AMT process selection

In the following sections this procedure is applied to two case studies as application examples.

\subsection{Example of application}

The parts analyzed in the context of this work are presented in Fig. 8.

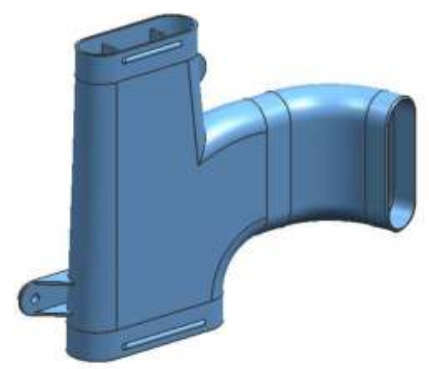

Part 1 - Air duct

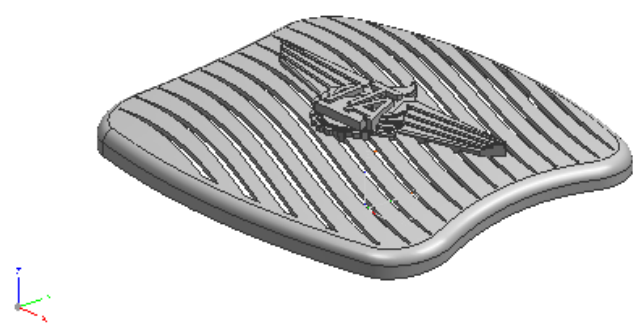

Part 2 - Decoration part

Fig. 8. Representative parts

The first part consists of an air duct. The main features are associated to the complex shape and the usual need for assemblies and fixture elements, which were integrated in the design. Part two represents a customized panel, which could include logos, as represented. Esthetical aspects and flexibility to produce different forms at low lot sizes represent great importance to consider the manufacturing process. Air duct is a typical example of AMT in the aircraft industry (DeGrange, 2006; Hopkinson et. al., 2006; Aerospace Engineering, 2004). 
The part was modelled including features which are not usually integrated, as fixture elements, one-piece-body and internal walls to direct air flow. Some part requirements are presented in Table 18.

\begin{tabular}{|c|c|}
\hline Requirements & \\
\hline Constructive & Max. dimensions: 69; 204; $160 \mathrm{~mm}$ \\
\hline Strength & Good properties in all directions \\
\hline Geometrical & $\begin{array}{l}\text { Duct with curvature in two directions, } \\
\text { wall thickness } 1,5 \mathrm{~mm} \text {, } \\
\text { max. form deviation } 0,5 \mathrm{~mm} / 100 \mathrm{~mm} \text {. }\end{array}$ \\
\hline Processing & Coating and sealing required \\
\hline Chemical & Flammability, \\
\hline
\end{tabular}

Table 18. Air duct requirements

After applying the verification procedure described in Fig, 6, it was observed that both FDM and SLS processes meet the requirements. In order to enable support structures removal the part produced by FDM had to be correctly positioned related to the build up direction. SLS enable also the integration of additional functions compared to FDM, exemplified by the introduction of a diffusor at one extremity. This part was produced by both processes, FDM and SLS, as Fig. 9.

Due to the support structures need, the FDM building process was restricted to one build up direction. This part positioning related to the layers was selected to avoid deposition of support material in regions where its removal could not be done.

The satisfied product requirements in Table 18 are not used anymore, but the relevant quality aspects, which are aggregated in Table 19. These aspects have to be in mind to the next phase of selection procedure. Relevant aspects are related to requirements which can be performed more efficiently by using AMT resulting in desired part improvements. Requirements as accuracy specified as being less then a certain value usually do not improve product quality. They should be considered as a filter to eliminate inadequate processes. However, higher tensile strength materials may be used to reduce weight, which may be a product improvement. Evidently, if one process can not satisfy one or more requirements, it should be excluded form the selection process.

SLS

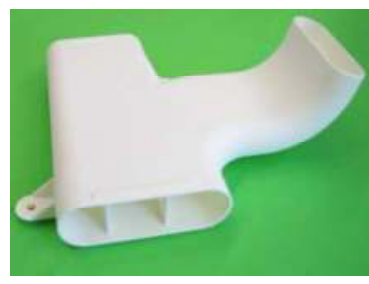

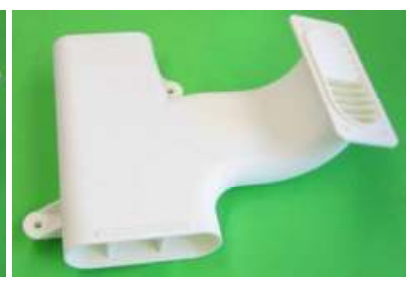

FDM

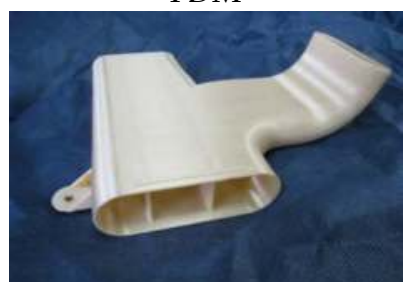

Fig. 9. AMT manufactured air ducts 


\begin{tabular}{ccc}
\hline Requirements & SLS & FDM \\
\hline $\begin{array}{c}\text { Constructive } \\
\text { Strength }\end{array}$ & Better form flexibility because no support & Restrictions due to \\
structures are required & Better isotropic material behavior \\
seometrical & Duct with curvature in two directions, wall & \\
thickness 1,5 mm & \\
\hline
\end{tabular}

Table 19. Aggregated process attributes for air duct part

As described, the second process selection method phase consists on creating the rank based on weightening quality, cost and time according user needs. Typical applications require low cost. Sometimes the time may be more important or even the quality. In order to exemplify, the next estimations are presented as cost preference, it means that cost is preferred instead of delivery time and quality. How much cost is preferred will be defined using requirements prioritization within AHP method.

\section{Cost preference}

Considering three alternatives and three requirements, four matrices should be filled with pairweise comparisons. The first one refers to comparison among the requirements to identify their priorities. Following, all the alternatives have to be compared considering each requirement. As this example has three major requirements (cost, time and quality), three additional matrices are required.

The decision team should fill these matrices with judgments according the fundamental scale of Saaty (Saaty, 2000), presented in Table 2. As quantitative requirements are presented (cost and delivery time), it is possible to fill the matrices with their rates instead of Saaty's fundamental scale. In this case, one should take care to notice whether the desired values are the higher or the lower ones.

The priority related to each matrix is represented by its eigenvector, thus, they have to be calculated to all matrices. A matrix is built assembling the resulting eigenvectors from the alternatives comparison matrices. This resulting matrix, in turn, is then multiplied by the eigenvector resulting from the requirements comparison table.

This example considers the costs as being stronger than other requirements. As possible judgments, it was considered that cost is strongly preferred than quality and time delivery, and quality slightly then time. These judgments have to be translated into a matrix, represented in Table 20.

\begin{tabular}{ccccc}
\hline & Cost & Quality & Time & Eigenvector \\
\hline Quality & $1 / 7$ & 1 & 2 & 0,1392 \\
Cost & 1 & 7 & 7 & 0,7732 \\
Time & $1 / 7$ & $1 / 2$ & 1 & 0,0877 \\
& $\lambda_{\max }=3,0536 ; \mathrm{CI}=0,0268 ; \mathrm{CR}=0,0516$ & \\
\hline
\end{tabular}

Table 20. Requirements comparison matrix

The eigenvector presented in Table 20 represents a numerical ranking of the requirements. It translates the decision team preferences into numerical values. The ordering also reflects intensity as indicated by the ratios of the numerical values. It is worth noticing that the AHP allows certain inconsistencies, which are represented by the CR. CR values less than $10 \%$ $(0,1)$ are considered acceptable (Saaty, 1977). If CR is greater than $10 \%$, the judgments have 
to be revised. In this example, the inconsistency relies on the fact that cost has the same importance rate to quality and time, however quality is judged more important then time.

The next step consists on compare the alternatives considering each requirement. At this point, quality is represented by extra functionality which may be performed using AMT, according Table 19. Time and cost were analyzed in the reference (Borille, 2009).

Table 21 represents the judgments related to quality of the processes. As SLS allows the integration of additional functions, it is considered more important than FDM. FDM in turn, makes it possible the integration of fixture elements when compared to conventional processes, thus, being also more important then conventional processes.

\begin{tabular}{ccccc}
\hline Quality & SLS & FDM & Conventional & Eigenvector \\
\hline SLS & 1 & 3 & 7 & 0,6694 \\
FDM & $1 / 3$ & 1 & 3 & 0,2426 \\
Conventional & $1 / 7$ & $1 / 3$ & 1 & 0,0879 \\
& $\lambda_{\max }=3,0070 ; \mathrm{CI}=0,0035 ; \mathrm{CR}=0,0068$ & \\
\hline
\end{tabular}

Table 21. Alternative matrix for requirement quality

Regarding cost and time, this example uses the values obtained from service provides. Different service providers offer different prices and delivery times. The costs are resumed in Table 22. Time is considered as being the delivery time of the first produced part. As cost is preferred, the less expensive alternatives were selected.

\begin{tabular}{cccc}
\hline & \multicolumn{2}{c}{ AMT } & Conventional \\
\hline SLS & FDM & \\
Cost [RS\$] & $1.674,40$ & $1.371,06$ & Variable according number of parts \\
$\begin{array}{c}\text { Time [business } \\
\text { days] }\end{array}$ & 3 & 7 & 20 \\
\hline
\end{tabular}

Table 22. Cost and time for purchasing the air duct part

Conventional process costs per unit are strongly dependent on quantity of produced parts. Costs estimation will be used to define the minimal batch size, which conventional process becomes preferable then AMT. This number is called Break-even-point (Zäh, 2006). Table 23 represents the team's judgments regarding time. Table 24 exemplifies the judgments for requirement cost. As quantitative values are available, they are used instead of building another comparison matrix. The costs are normalized and their inverse values are used because lower costs are desired. In order to simulate diverse batch sizes, Table 24 was reproduced using different values of conventional process cost per unit.

\begin{tabular}{ccccc}
\hline Time & SLS & FDM & Conventional & Eigenvector \\
\hline SLS & 1 & 3 & 5 & 0,6370 \\
FDM & $1 / 3$ & 1 & 3 & 0,2583 \\
Conventional & $1 / 5$ & $1 / 3$ & 1 & 0,1047 \\
& $\lambda_{\max }=3,0385 ; \mathrm{CI}=0,0193 ; \mathrm{CR}=0,0370$ & \\
\hline
\end{tabular}

Table 23. Alternative matrix for requirement time 


\begin{tabular}{ccc}
\hline & Cost [RS\$] & Preference \\
\hline SLS & $1.674,40$ & 0,3919 \\
FDM & $1.371,06$ & 0,4786 \\
Conventional process (10 parts) & $5.069,69$ & 0,1294 \\
\hline
\end{tabular}

Table 24. Alternative matrix for requirement cost - example for 10 parts

The final ranking results from multiplying the matrices presented in Table 25. In this case, for ten parts, SLS process would be selected with $45 \%$ of preference, although FDM is the cheapest alternative.

\begin{tabular}{|c|c|c|c|c|c|}
\hline & Quality & Cost & Time & Requirements & Ranking \\
\hline SLS & 0,6694 & 0,3919 & 0,6370 & 0,1392 & 0,4521 \\
\hline FDM & 0,2426 & 0,4786 & 0,2583 & 0,7732 & 0,4265 \\
\hline Conventional & 0,0879 & 0,1294 & 0,1047 & 0,0877 & 0,1215 \\
\hline
\end{tabular}

Table 25. Final ranking generation (10 parts)

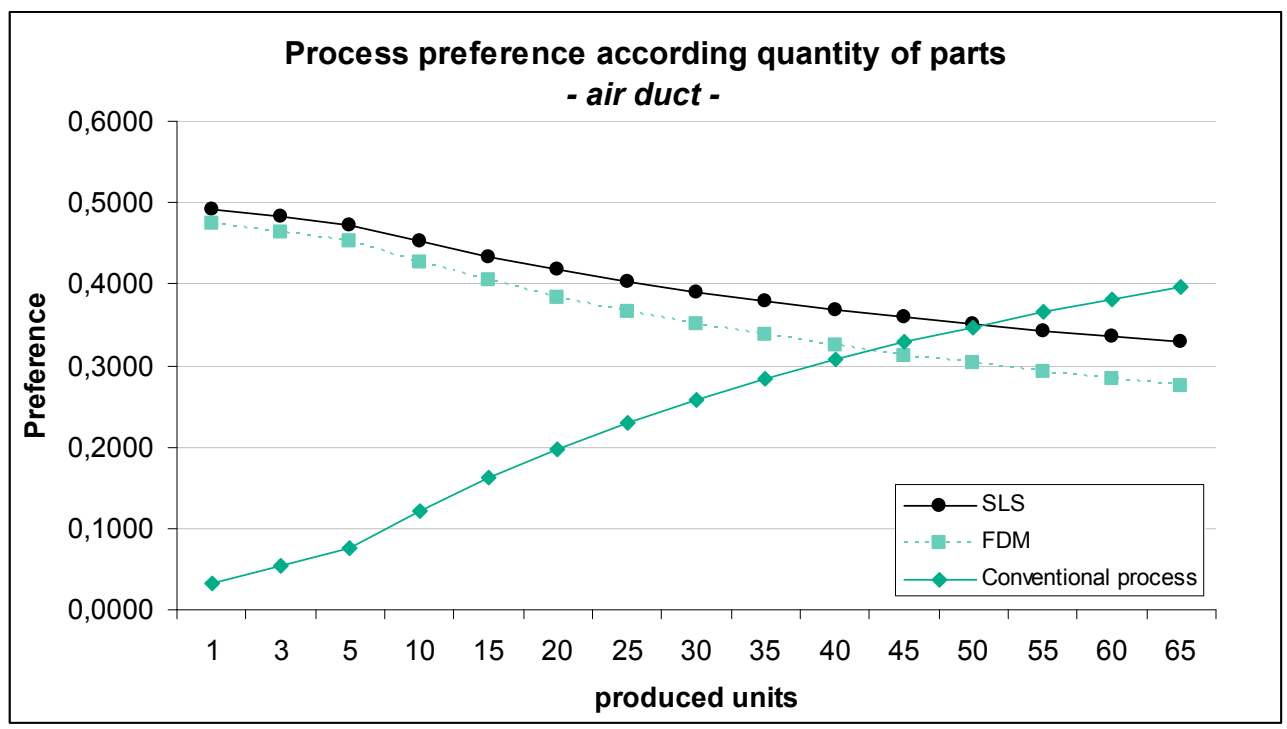

Fig. 10. Simulation of process preference quantity of produced parts for part 1

Varying the quantity of produced parts, conventional injection molding process becomes preferred because the cost per part decreases significantly. Using the proposed procedure, one can estimate the break-even-point. 
Fig. 10 shows that, in this case, SLS process would be preferred until batch sizes of approximately 50 parts. Larger batches should be produced using injection molding.

When AMT batch size becomes larger, it should be considered that the produced parts delivery time may increase depending on the machine capacity of the service provider. The price per part, in this case, may also be reduced due to the better machine usage, specially when considering SLS (Borille, 2009).

\section{Case two: interior decoration part}

The same selection procedure was applied to the part two, an example of decoration part. The quality attributes are aggregated in Table 26, which presented also the manufactured parts.

\begin{tabular}{c|c}
\hline Requirements & SLS \\
\hline Geometrical & $\begin{array}{c}\text { Better visual surface quality, } \\
\text { Higher distortions }\end{array}$ \\
Strength & $\begin{array}{c}\text { Restricted to one building direction } \\
\text { due to stair-step effect } \\
\text { Higher resistance and rigidity in } \\
\text { such a planar part leads to lower } \\
\text { weight }\end{array}$ \\
\hline
\end{tabular}

Table 26. Aggregated process attributes for decoration part

The decision team faced the following situation: the customers needs consist on the quickly customization of its aircraft. As requirements, the decision team built up the following requirements matrix, Table 27

\begin{tabular}{ccccc}
\hline & Quality & Cost & Time & Eigenvector \\
\hline Quality & 1 & 3 & $1 / 3$ & 0,2308 \\
Cost & $1 / 3$ & 1 & $1 / 9$ & 0,0769 \\
Time & 3 & 9 & 1 & 0,6923 \\
& $\lambda_{\max }=3,0000 ; \mathrm{CI}=0,0000 ; \mathrm{CR}=0,0000$ & \\
\hline
\end{tabular}

Table 27. Requirements comparison matrix for decoration part

Table 28 presents the decision team judgments for quality, according considerations from Table 26. Although the better surface quality of SLS, the FDM process may produce stronger planar parts due to its higher tensile resistance. SLS and FDM are considered as the same importance. Injection molding process presents some restrictions due to draft angles to allow the mold opening, thus, it was considered less important. 


\begin{tabular}{ccccc}
\hline Quality & SLS & FDM & Conventional & Eigenvector \\
\hline SLS & 1 & 3 & 3 & 0,4286 \\
FDM & 1 & 1 & 3 & 0,4286 \\
Conventional & $1 / 3$ & $1 / 3$ & 1 & 0,1429 \\
& $\lambda_{\max }=3,0000 ; \mathrm{CI}=0,0000 ; \mathrm{CR}=0,0000$ & \\
\hline
\end{tabular}

Table 28. Alternative matrix for requirement quality

When purchasing the fastest alternatives from service providers, the cost values are used to judge the alternatives regarding time in

Table 29 and to build the cost rates in

Table 30.

\begin{tabular}{ccccc}
\hline Time & SLS & FDM & Conventional & Eigenvector \\
\hline SLS & 1 & 2 & 9 & 0,5969 \\
FDM & $1 / 2$ & 1 & 7 & 0,3458 \\
Conventional & $1 / 9$ & $1 / 7$ & 1 & 0,0572 \\
& $\lambda_{\max }=3,0217 ; \mathrm{CI}=0,0109 ; \mathrm{CR}=0,0209$ & \\
\hline
\end{tabular}

Table 29. Alternative matrix for requirement time

\begin{tabular}{ccc}
\hline & Cost [RS\$] & Preference \\
\hline SLS & 1034,80 & 0,6025 \\
FDM & 1040,00 & 0,3284 \\
Conventional process (5 parts) & 4945,44 & 0,0691 \\
\hline
\end{tabular}

Table 30. Alternative matrix for requirement cost - example for 5 parts

The final ranking results from multiplying the matrices presented in

Table 31. In this case, for five parts, SLS process would be selected with $55 \%$ of preference.

\begin{tabular}{cccccccc}
\hline & Quality & Cost & Time & & Requirements & & Ranking \\
\cline { 1 - 3 } \cline { 7 - 8 } SLS & 0,4286 & 0,6025 & 0,5969 & & 0,2308 & & 0,5585 \\
FDM & 0,4286 & 0,3284 & 0,3458 & & 0,0769 & & 0,3636 \\
Conventional & 0,1429 & 0,0691 & 0,0572 & & 0,6923 & & 0,0779 \\
\hline
\end{tabular}

Table 31. Final ranking generation - decoration part

SLS process was selected because it had in this example the lower price and the shorter delivery time. In this example, the cost per part reduction of injection molding could not overcome the time requirement. 
Fig. 11 represents the preference ranking. Injection molding would be effective only when the parts quantity become high enough to imply in higher SLS delivery time.

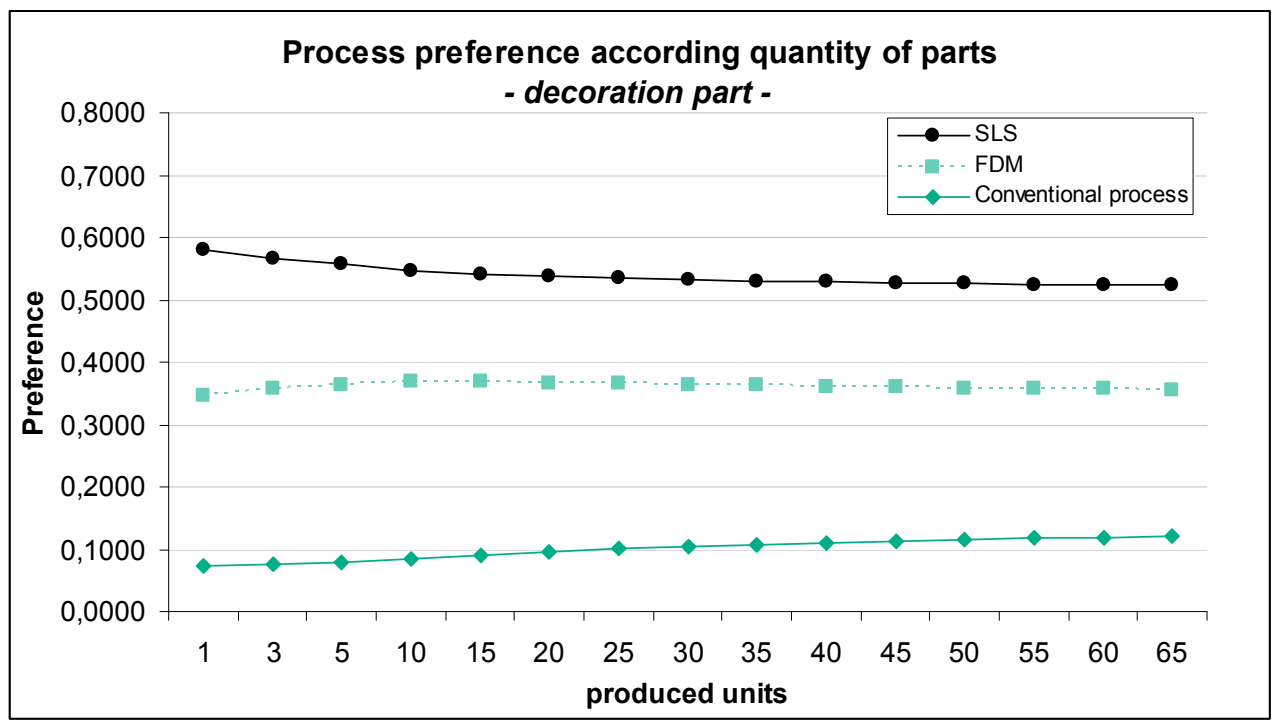

Fig. 11. Simulation of process preference quantity of produced parts for part 2

\section{Conclusion}

Rapid Manufacturing is becoming reality in several industries, among them the aeronautical. New machine and the further material developments allow the continuous expansion of applications. Grimm (2004) mentioned that there was at that time no machine with focus on RM. Three years later, Arcam presented the machine called A2, which is considered the first one focused on RM applications (Arcam, 2007). Further examples of these trends were presented at the Euromold 2008 trade fair, in Frankfurt, Germany. Stratasys as well as EOS presented new material options and new machines. Ultem $\odot$ for FDM equipments and PEEK for SLS are both high performance polymers and potential candidates to be used in aircraft applications by means of AMT.

The introducing into the market of both new materials choices as well new machine generations are important indicators of the aircraft industry market importance. However, the method suggested in this work could be applied not only for aeronautical applications. It could also more options to compare and choose the best alternative considering also the new alternatives. 
Another point which would contribute to the implementation of this procedure is the definition of metrics to aggregate components according geometrical similarity. The presented work was based on visual similarities to select models as representative geometries and proposed the individual cost and build time estimation. But users could develop definitions of metrics which could represent groups of parts. It could accelerate the cost and time estimation.

Make or buy decision could also be done based on results from the proposed procedure. The point to be analysed is the estimation of quantity of parts that the company would like to produce. This quantity should be used to calculate the machine cost per hour, which is one of major cost factor.

\section{Acknowledgment}

The authors would like to thank especially Prof. Dr.-Ing. Karl-Heinrich Grote at Otto-vonGuericke University and Dr. Rudolf Meyer at Fraunhofer IFF in Magdeburg and also Prof. Dr.-Ing. Fritz Klocke at RWTH and Dipl.-Ing. Axel Demmer at Fraunhofer IPT in Aachen, Last but not least, this work could not have been completed without the financial support from FAPESP (Fundação de Amparo à Pesquisa do Estado de São Paulo), FINEP (Financiadora de Estudos e Projetos), CNPq (Conselho Nacional de Desenvolvimento Científico e Tecnológico), CAPES (Coordenação de Aperfeiçoamento de Pessoal de Nível Superior) and DAAD (Deutscher Akademischer Austausch Dienst).

\section{References}

Borille, A. V. Decision support method to apply Additive Manufacturing Technologies for plastic components in the aircraft industry. Thesis of doctor in science - Program of Mechanics Engineering, area of Aerospace Systems and Mechatronics. Technological Institute of Aeronautics. São José dos Campos, 2009.

Borille, A. V., Gomes, J. O., Grote, K.-H., Meyer, R. The use of decision methods to select Rapid Prototyping technologies, Rapid Prototyping Journal. Paper approved for publishing in issue 1, Vol 16, 2010

Byun, H. S., Lee, K. H. (2005). A decision support system for the selection of rapid prototyping process using the modified TOPSIS method. International Journal of Advanced Manufacturing Technology, Vol 26, pg 1338-1347.

Katschka, U. Methodik zur Entscheidungsunterstützung bei der Auswahl und Bewertung von Konventionellen und Rapid Tooling-Prozessketten. PhD thesis. Technische Universität Chemnitz. Shaker Verlag. ISBN 3-8265-6431-6, 1999.

Rao, R. V., Padmanabhan, K. K. (2007). Rapid Prototyping process selection using graph theory and matrix approach. Journal of Materials Processing Technolog, Volume 194, Issues 1-3, 1 November, Pages 81-88.

Saaty, T. L. (2003) Decisiont-making with the AHP: Why is the principal eigenvector necessary, European Journal of Operational Research, Vol. 145, pp. 85-91.

VDI 2225 (1998). Konstruktionsmethodik: Technisch-witschaftliches Konstruiren, technischwitschaftliche Bewertung. Verein Deutscher Ingenieure, November. 
VDI 3404 (2007). Generative Fertigungsverfahren: Rapid-Technologiens (Rapid Prototyping) Grundlagen, Begriffe, Qualitätskenngrößen, Liefervereinbarungen. Verein Deutscher Ingenieure, December.

Zäh, Michael F. (2006). Wirtschaftliche Fertigung mit Rapid-Technologien. Anwender-Leitfaden zur Auswahl geeigneter Verfahren. Hanser Verlag. ISBN 3-446-22854-3 


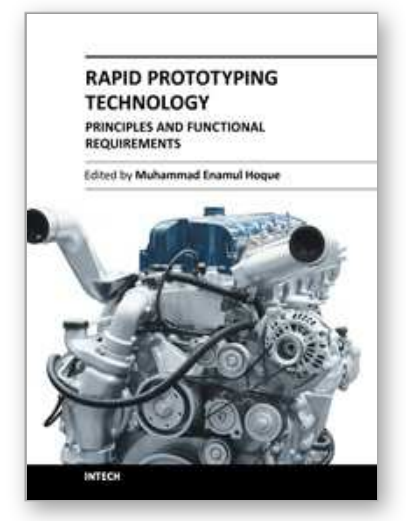

\section{Rapid Prototyping Technology - Principles and Functional Requirements}

Edited by Dr. M. Hoque

ISBN 978-953-307-970-7

Hard cover, 392 pages

Publisher InTech

Published online 26, September, 2011

Published in print edition September, 2011

Modern engineering often deals with customized design that requires easy, low-cost and rapid fabrication. Rapid prototyping (RP) is a popular technology that enables quick and easy fabrication of customized forms/objects directly from computer aided design (CAD) model. The needs for quick product development, decreased time to market, and highly customized and low quantity parts are driving the demand for RP technology. Today, RP technology also known as solid freeform fabrication (SFF) or desktop manufacturing (DM) or layer manufacturing (LM) is regarded as an efficient tool to bring the product concept into the product realization rapidly. Though all the RP technologies are additive they are still different from each other in the way of building layers and/or nature of building materials. This book delivers up-to-date information about RP technology focusing on the overview of the principles, functional requirements, design constraints etc. of specific technology.

\section{How to reference}

In order to correctly reference this scholarly work, feel free to copy and paste the following:

Anderson Vicente Borille and Jefferson de Oliveira Gomes (2011). Selection of Additive Manufacturing Technologies Using Decision Methods, Rapid Prototyping Technology - Principles and Functional Requirements, Dr. M. Hoque (Ed.), ISBN: 978-953-307-970-7, InTech, Available from: http://www.intechopen.com/books/rapid-prototyping-technology-principles-and-functionalrequirements/selection-of-additive-manufacturing-technologies-using-decision-methods

\section{INTECH}

open science | open minds

\section{InTech Europe}

University Campus STeP Ri

Slavka Krautzeka 83/A

51000 Rijeka, Croatia

Phone: +385 (51) 770447

Fax: +385 (51) 686166

www.intechopen.com

\section{InTech China}

Unit 405, Office Block, Hotel Equatorial Shanghai

No.65, Yan An Road (West), Shanghai, 200040, China

中国上海市延安西路65号上海国际贵都大饭店办公楼 405 单元

Phone: +86-21-62489820

Fax: +86-21-62489821 
(C) 2011 The Author(s). Licensee IntechOpen. This chapter is distributed under the terms of the Creative Commons Attribution-NonCommercialShareAlike-3.0 License, which permits use, distribution and reproduction for non-commercial purposes, provided the original is properly cited and derivative works building on this content are distributed under the same license. 